\title{
STUDI KESESUAIAN PANTAI LAGUNA DESA MERPAS KECAMATAN NASAL KABUPATEN KAUR SEBAGAI DAERAH PENGEMBANGAN PARIWISATA DAN KONSERVASI
}

\author{
Oleh \\ Gesten Hazeri ${ }^{1}$, Dede Hartono ${ }^{1 *}$ dan Indra Cahyadinata ${ }^{2}$ \\ ${ }^{1}$ Program Studi Ilmu Kelautan Fakultas Pertanian Universitas Bengkulu, Bengkulu \\ ${ }^{2}$ Program Sosial Ekonomi Pertanian Fakultas Pertanian Universitas Bengkulu, Bengkulu \\ "Email: perikanan_unib@yahoo.com
}

Received February 2016, Accepted March 2016

\begin{abstract}
ABSTRAK
Pariwisata adalah segala sesuatu yang berhubungan dengan wisata, termasuk pengusahaan objek dan daya tarik wisata serta usaha-usaha yang terkait dibidang tersebut. Penelitian ini bertujuan untuk mengkaji kesesuaian pantai laguna untuk aktivitas pariwisata bahari yang meliputi : Wisata bahari, Wisata pantai, dan Kawasan konservasi. Metode yang digunakan adalah metode survei menggunakan kuesioner dan observasi langsung dengan melakukan pengamatan (pengukuran) langsung dilapangan, terdiri dari 3 stasiun pengamatan dengan pengulangan 3 kali. Hasil penelitian kecerahan pada Pantai Laguna adalah 100\%, tutupan karang hidup Pantai Laguna yaitu sebesar 31,66\% dengan kodisi sedang, jenis karang 129 jenis yang termasuk kedalam 37 marga dan 15 suku, ikan karang 113 spesies yang masuk dalam 27 suku, kecepatan arus rata-rata perairan Pantai Laguna adalah $0,053 \mathrm{~m} / \mathrm{dtk}$, kedalaman perairan pantai Laguna relative dangkal yaitu rata-rata $0,87 \mathrm{~m}$, Material dasar perairan adalah karang berpasir, tipe pantai adalah berpasir sedikit karang, penutupan lahan Pantai Laguna adalah belukar tinggi, jarak ketersediaan air tawar di Pantai Laguna adalah 60 meter, kemiringan Pantai Laguna dengan kemiringan 13,9 ${ }^{\circ}$ (landai), jarak Pantai Laguna 300 meter dari jalan lintas utama, jenis tanah Pantai Laguna adalah endapan pasir dan lumpur (aluvial pantai), ketinggian Pantai Laguna $1,05 \mathrm{~m}$ atau $105 \mathrm{~cm}$ dari bibir pantai dan sisi pantai tertinggi, drainase Pantai Laguna tidak tergenang, vegetasi Pantai Laguna non mangrove. Pantai Laguna memiliki indeks kesesuaian sebagai wisata bahari pada kategori S1: Bagus (Sangat Sesuai) dengan nilai indeks $77 \%$, indeks kesesuaian sebagai wisata pantai pada kategori S1 : Bagus (Sangat Sesuai) dengan nilai indeks $82,7 \%$, indeks kesesuaian sebagai kawasan konservasi pada kategori S1: Bagus (Sangat Sesuai) dengan nilai indeks $86,2 \%$.
\end{abstract}

Kata kunci : Kesesuaian, pantai laguna, pengembangan, bahari. 


\section{PENDAHULUAN}

Wisata bahari merupakan suatu bentuk wisata potensial termasuk di dalam kegiatan "industri bersih". Pelaksanaan wisata bahari yang berhasil apabila memenuhi berbagai komponen yakni terkaitnya dengan kelestarian lingkungan alami, kesejahteraan penduduk yang mendiami wilayah tersebut, kepuasan pengunjung yang menikmatinya dan keterpaduan komunitas dengan area pengembangannya (Nurisyah, 2002). Konsep wisata bahari di dasarkan pada view, keunikan alam, karakteristik ekosistem, kekhasan seni budaya dan karaktersitik masyarakat sebagai kekuatan dasar yang dimiliki oleh masingmasing daerah.

Pantai Laguna adalah salah satu objek wisata Pantai yang cukup potensial dan direncanakan untuk segera akan dibenahi serta dikelola dengan baik. Secara tradisional lokasi ini sudah berfungsi serta beroperasi dengan baik dan menghasilkan keuntungan bagi masyarakat Kaur khususnya bagi kecamatan Nasal. Pantai Laguna Samudera ini terletak di sisi jalan Lintas Barat Sumatera dan berada di baris paling pertama dari arah Lampung melalui jalan darat. Sehingga Pantai Laguna Samudera sangat ideal menjadi titik penyebaran (distribution point) wisatawan yang berasaldari pulau Jawa ke objek-objek wisata lain di Provinsi Bengkulu (Dinas Perikanan dan Kelautan Kabupaten Kaur, 2009).

\section{METODE PENELITIAN}

\section{Tempat dan Waktu Penelitian.}

Penelitian dilaksanakan pada bulan Agustus 2014, di Pantai Laguna yang merupakan salah satu objek wisata di Desa Merpas Kecamatan Nasal Kabupaten Kaur Provins Bengkulu.

Data.

Jenis data yang digunakan dalam penelitian ini terdiri dari data primer dan data sekunder. Data primer merupakan data yang diperoleh langsung dari lokasi penelitian melalui observasi, survey dan wawancara dengan masyarakat dan stakeholder terkait. Sedangkan data sekunder merupakan jenis data yang diperoleh dari data penelitian terdahulu yang pernah dilakukan sebelumnya dan studi kepustakaan di dinas atau instansi terkait dalam bentuk laporan dan publikasi.

\section{Analisis Tingkat Kesesuaian.}

1) Wisata Bahari

Kesesuaian lahan untuk wisata bahari dapat didefinisikan sebagai suatu tingkat kecocokan suatu lahan untuk kepentingan wisata bahari yang meliputi berbagai parameter sebagai berikut. 
Tabel 1. Analisis Kesesuaian Wisata Bahari

\begin{tabular}{|c|c|c|c|c|c|c|c|c|c|c|}
\hline \multirow[t]{2}{*}{ No } & \multirow[t]{2}{*}{ Parameter } & \multirow[t]{2}{*}{ Bobot } & \multicolumn{8}{|c|}{ Kategori dan Skor } \\
\hline & & & Kategori & Skor & Kategori & Skor & Kategori & Skor & Kategori & Skor \\
\hline 1 & $\begin{array}{l}\text { Kecerahan perairan } \\
(\%)\end{array}$ & 4 & $>75$ & 4 & $>50-75$ & 3 & $>25-50$ & 2 & $<25$ & 1 \\
\hline 2 & $\begin{array}{l}\text { Tutupan Karang } \\
\text { Hidup (\%) }\end{array}$ & 7 & $>75$ & 4 & $>50-75$ & 3 & $>25-50$ & 2 & $<25$ & 1 \\
\hline 3 & $\begin{array}{l}\text { Jenis Karang } \\
\text { (species) }\end{array}$ & 4 & $>100$ & 4 & $>75-100$ & 3 & $>20-50$ & 2 & $<20$ & 1 \\
\hline 4 & $\begin{array}{l}\text { Jenis Ikan Karang } \\
\text { (Species) }\end{array}$ & 4 & $>70$ & 4 & $>50-70$ & 3 & $>20-50$ & 2 & $<20$ & 1 \\
\hline 5 & $\begin{array}{l}\text { Kecepatan Arus } \\
\text { (m/det) }\end{array}$ & 3 & $0-0.17$ & 4 & $\begin{array}{l}>0.17- \\
0.34\end{array}$ & 3 & $\begin{array}{c}>0.34- \\
0.51\end{array}$ & 2 & $>0.51$ & 1 \\
\hline 6 & $\begin{array}{l}\text { Kedalaman } \\
\text { Perairan }(\mathrm{m})\end{array}$ & 3 & $>10-25$ & 4 & $>5-10$ & 3 & $>2-5$ & 2 & $<2$ & 1 \\
\hline
\end{tabular}

Sumber : Bakosurtanal (1996); Arifin, T (2000).

\section{2) Wisata Pantai}

Kesesuaian lahan untuk wisata pantai dapat didefinisikan sebagai suatu tingkat kecocokan suatu lahan untuk kepentingan wisata pantai yang meliputi berbagai parameter sebagai berikut.

Tabel 2. Analisis Kesesuaian Wisata Pantai

\begin{tabular}{|c|c|c|c|c|c|c|c|c|c|c|}
\hline \multirow[t]{2}{*}{ No } & \multirow[t]{2}{*}{ Parameter } & \multirow[t]{2}{*}{ Bobot } & \multicolumn{8}{|c|}{ Kategori dan Skor } \\
\hline & & & Kategori & Skor & Kategori & Skor & Kategori & Skor & Kategori & Skor \\
\hline 1 & $\begin{array}{l}\text { Kedalaman } \\
\text { perairan }(\mathrm{m})\end{array}$ & 4 & $0-5$ & 4 & $>5-10$ & 3 & $>10$ & 2 & - & - \\
\hline 2 & $\begin{array}{l}\text { Material dasar } \\
\text { perairan }\end{array}$ & 4 & Pasir & 4 & $\begin{array}{l}\text { Karang } \\
\text { berpasir }\end{array}$ & 3 & $\begin{array}{c}\text { Pasir } \\
\text { berlumpur }\end{array}$ & 2 & Lumpur & 1 \\
\hline 3 & $\begin{array}{l}\text { Kecepatan arus } \\
\text { (m/det) }\end{array}$ & 4 & $0-0,17$ & 4 & $\begin{array}{l}>0.17- \\
0.34\end{array}$ & 3 & $0.34-0.51$ & 2 & $>0.51$ & 1 \\
\hline 4 & $\begin{array}{l}\text { Kecerahan perairan } \\
(\%)\end{array}$ & 4 & $>75$ & 4 & $>50-75$ & 3 & $>25-50$ & 2 & $<25$ & 1 \\
\hline 5 & Tipe pantai & 7 & Berpasir & 4 & $\begin{array}{l}\text { Berpasir, } \\
\text { sedikit } \\
\text { karang }\end{array}$ & 3 & $\begin{array}{l}\text { Pasir dan } \\
\text { berkarang, } \\
\text { sedikit terjal }\end{array}$ & 2 & $\begin{array}{l}\text { Lumpur, } \\
\text { karang, } \\
\text { terjal, } \\
\text { mangrov } \\
\text { e }\end{array}$ & 1 \\
\hline 6 & $\begin{array}{l}\text { Penutupan lahan } \\
\text { pantai }\end{array}$ & 3 & $\begin{array}{l}\text { Kelapa, } \\
\text { lahan } \\
\text { terbuka }\end{array}$ & 4 & $\begin{array}{l}\text { Semak, } \\
\text { belukar, } \\
\text { savana }\end{array}$ & 3 & $\begin{array}{l}\text { Belukar } \\
\text { tinggi }\end{array}$ & 2 & $\begin{array}{c}\text { Bakau, } \\
\text { pemukim } \\
\text { an, } \\
\text { pelabuha } \\
n\end{array}$ & 1 \\
\hline 7 & $\begin{array}{l}\text { Jarak ketersediaan } \\
\text { air tawar }(\mathrm{km})\end{array}$ & 3 & $<0.5$ & 4 & $0.5-1$ & 3 & $>1-2$ & 2 & $>2$ & 1 \\
\hline
\end{tabular}

Sumber : Arifin, T (2000)

3) Kawasan konservasi

Kesesuaian lahan untuk kawasan konservasi adalah suatu tingkat kecocokan suatu lahan untuk kawasan konservasi yang meliputi berbagai parameter sebagai berikut. 
Tabel 3. Analisis Kesesuaian Kawasan Konservasi

\begin{tabular}{llccccccccc}
\hline No & Parameter & Bobot & \multicolumn{7}{c}{ Kategori dan Skor } \\
\cline { 3 - 10 } & & Kategori & Skor & Kategori & Skor & Kategori & Skor & Kategori & Skor \\
\hline 1 & Kemiringan $\left(^{\circ}\right)$ & 0,10 & $0-2$ & 4 & $3-5$ & 3 & 6 & 2 & $>6$ & 1 \\
\hline 2 & Jarak pantai $(\mathrm{m})$ & 0,30 & $<100$ & 4 & $200-300$ & 3 & $300-400$ & 2 & $>400$ & 1 \\
\hline 3 & Jenis tanah & 0,15 & $\begin{array}{c}\text { Aluvial } \\
\text { Pantai }\end{array}$ & 4 & Hidromorf & 3 & $\begin{array}{c}\text { Rigosol, } \\
\text { gleihumus }\end{array}$ & $\begin{array}{c}\text { Gleihumus } \\
\text {, rigosol }\end{array}$ & 1 \\
\hline 4 & Ketinggian $(\mathrm{cm})$ & 0,10 & $0-5$ & 4 & $6-15$ & 3 & $16-20$ & 2 & $>21$ & 1 \\
\hline 5 & Drainase & 1,15 & $\begin{array}{c}\text { Tidak } \\
\text { Tergena } \\
\text { ng }\end{array}$ & 4 & $\begin{array}{c}\text { Tergenang } \\
\text { priodek }\end{array}$ & 3 & Tergenang & 2 & - & 1 \\
\hline 6 & Bervegetasi & 0,20 & $\begin{array}{c}\text { Mangrov } \\
\text { e }\end{array}$ & 4 & $\begin{array}{c}\text { Non } \\
\text { Mangrove }\end{array}$ & 3 & - & 2 & - & 1 \\
\hline
\end{tabular}

Sumber : Candra (2003)

\section{Indeks kesesuaian wisata}

Rumus yang di gunakan untuk menghitung indeks kegiatan wisata adalah sebagai berikut :

Keterangan :

$$
\mathrm{IKW}=\sum\left[\frac{\mathrm{Ni}}{\mathrm{Nmaks}}\right] \times 100 \%
$$

$\mathrm{IKW} \quad=$ Indeks Keseuaian Wisata

$\mathrm{Ni} \quad=$ Nilai parameter ke-i (Bobot $\mathrm{x}$ skor)

Nmaks = Nilai maksimum dari suatu kategori wisata

Evaluasi terhadap parameter kesesuaian seperti tabel di atas mencakup 4 kelas dengan kriteria :

a. S1 : Nilai $75-100 \%$ : Bagus (sangat sesuai)

Suatu kawasan yang dikembangkan tidak mempunyai pembatas yang serius untuk menerapkan perlakuan yang diberikan atau hanya mempunyai pembatas yang tidak berarti atau tidak berpengaruh secara nyata terhadap penggunaannya dan tidak akan menaikkan masukan/tingkatan perlakuan yang diberikan.

b. S2 : Nilai $50-74 \%$ : Sesuai

Suatu kawasan memiliki pembatas-pembatas yang agak serius untuk mempertahankan tingkat perlakuan yang harus diterapkan. Pembatas ini akan meningkatkan mesukan/tingkatan perlakuan yang diperlukan.

c. S3 : Nilai $25-49 \%$ : Sesuai Bersyarat

Suatu daerah mempunyai pembatas-pembatas yang serius untuk mempertahankan tingkat perlakuan yang harus diterapkan. Pembatas akan lebih meningkatkan masukan perlakuan yang diperlukan.

d. N : Nilai < 25 : Tidak sesuai

Suatu daerah memiliki pembatas yang permanen, sehingga mencegah segala kemungkinan perlakuan pada daerah tersebut.

\section{HASIL DAN PEMBAHASAN}

\section{Wisata Bahari}

1. Kecerahan perairan

merupakan syarat utama dalam kegiatan pariwisata Bahari. Dimana semakin cerah suatu perairan semakin indah pula taman laut yang dapat dinikmati oleh wisatawan. Hasil penelitian kecerahan perairan di Pantai Laguna adalah : 
Tabel 4. Kecerahan Perairan pantai laguna

\begin{tabular}{|c|c|c|c|}
\hline No & Titik Sampling & Titik Koordinat & $\begin{array}{l}\text { Kecerahan } \\
(\%)\end{array}$ \\
\hline 1 & A1 & $4^{0} 55^{\prime} 01,37^{\prime \prime} \mathrm{S} 103^{0} 32^{\prime} 04,91^{\prime \prime} \mathrm{T}$ & 100 \\
\hline 2 & $\mathrm{~A} 2$ & $4^{0} 55^{\prime} 02,26$ "S $103^{0} 32^{\prime} 01,99^{\prime \prime} T$ & 100 \\
\hline 3 & A3 & $4^{0} 55^{\prime} 02,48$ "S $103^{0} 31^{\prime} 58,91^{\prime \prime} T$ & 100 \\
\hline
\end{tabular}

Sumber : Data primer, 2014

2. Tutupan Karang Hidup

Tutupan karang hidup menurut data dari Dinas Perikanan dan Kelauta Kabupaten Kaur bahwa persentase tutupan karang hidup yaitu sebesar $31,66 \%$ dengan kodisi sedang.

3. Jenis Karang

Berdasarkan data yang di dapatkan dari Dinas Perikanan dan Kelauta Kabupate Kaur didapatkan bahwa terdapat 129 jenis karang yang termasuk kedalam 37 marga dan 15 suku.

4. Jenis Ikan Karang

Berdasarkan data dari Dinas Perikanan dan Kelautan Kabupaten Kaur, dari hasil pegamatan ikan karang melalui underwataer fish visual cencus dijumpai 113 spesies ikan karang yang masuk dalam 27 suku. Susku terbayak adalah Labriade dengan 20 jenis ikan.

5. Kecepatan Arus

Hasil penelitian kecepatan arus di Pantai Laguna adalah :

Tabel 5. Kecepatan Arus pantai laguna

\begin{tabular}{|c|c|c|c|}
\hline No & Titik Sampling & Titik Koordinat & Kec. Arus (m/detik) \\
\hline 1 & A1 & $\begin{array}{c}4^{0} 55^{\prime} 01,37^{\prime \prime} \mathrm{S} \\
103^{0} 32^{\prime} 04,91^{\prime \prime} T\end{array}$ & 0,053 \\
\hline 2 & $\mathrm{~A} 2$ & $\begin{array}{c}4^{0} 55^{\prime} 02,26 " S \\
103^{0} 32,01,99^{\prime \prime} T\end{array}$ & 0,053 \\
\hline 3 & A3 & $\begin{array}{c}4^{0} 55^{\prime} 02,48 \text { "S } \\
103^{0} 31^{\prime} 58,91^{\prime \prime} T\end{array}$ & 0,054 \\
\hline
\end{tabular}

Sumber : Data primer, 2014

6. Kedalaman Perairan

Hasil penelitian kedalaman perairan di Pantai Laguna adalah :

Tabel 6 . Kedalaman Perairan pantai laguna

\begin{tabular}{cccc}
\hline No & Titik Sampling & Titik Koordinat & Kedalaman $(\mathrm{m})$ \\
\hline 1 & A1 & $4^{0} 55^{\prime} 01,37^{\prime \prime} \mathrm{S} 103^{0} 32^{\prime} 04,91^{\prime \prime} T$ & 1,14 \\
\hline 2 & A2 & $4^{0} 55^{\prime} 02,26^{\prime \prime} S 103^{0} 32^{\prime} 01,99^{\prime \prime} T$ & 0,61 \\
\hline 3 & A3 & $4^{0} 55^{\prime} 02,48^{\prime \prime} S 103^{0} 31^{\prime} 58,91^{\prime \prime} T$ & 0,84 \\
\hline & & Kedalaman rata-rata & 0,87
\end{tabular}

Sumber : Data primer, 2014

Dari hasil pengukuran yang telah diperoleh. Maka peneliti menganalisis kesesuaian berdasarkan aspek penilaian yang disesuaikan dalam tabel parameter kesesuaian wisata bahari untuk memperoleh tingkat kesesuaiannya. 
Tabel 7. Hasil analisis kesesuaian wisata bahari

\begin{tabular}{|c|c|c|c|c|c|c|}
\hline Parameter & Bobot & & Skor & & $\mathrm{B} \times \mathrm{S}(\mathrm{Ni})$ & $\mathrm{N}$ maks \\
\hline Kecerahan (\%) & 4 & 100 & DP & 4 & 16 & 16 \\
\hline Tutupan Karang Hidup (\%) & 7 & 31,66 & DS & 2 & 14 & 28 \\
\hline Jenis Karang & 4 & 129 & DS & 4 & 16 & 16 \\
\hline Jenis Ikan Karang & 4 & 113 & DS & 4 & 16 & 16 \\
\hline Kecepatan Arus (Km/det) & 3 & 0,053 & DP & 4 & 12 & 12 \\
\hline Kedalaman $(\mathrm{m})$ & 3 & 0,87 & $\mathrm{DP}$ & 1 & 3 & 12 \\
\hline Jumlah & & & & & 77 & 100 \\
\hline
\end{tabular}

Keterangan : DP (Data Primer), DS (Data Sekunder)

$$
\mathrm{IKW}=\sum\left[\frac{\mathrm{Ni}}{\mathrm{Nmaks}}\right] \times 100 \%
$$

Berdasarkan hasil penelitian analisis kesesuaian lokasi wisata di pantai Laguna didapatkan nilai $77 \%$. Ini berarti, Pantai Laguna bagus (sangat sesuai) dikembangkan untuk wisata bahari.

\section{Wisata Pantai}

1. Kedalaman Perairan Hasil penelitian kedalaman perairan di Pantai Laguna adalah :

Tabel 8 . Kedalaman Perairan pantai laguna

\begin{tabular}{|c|c|c|c|}
\hline No & Titik Sampling & Titik Koordinat & Kedalaman (m) \\
\hline 1 & $\bar{A} 1$ & $\begin{array}{c}4^{0} 55^{\prime} 01,37^{\prime \prime} \mathrm{S} \\
103^{0} 32^{\prime} 04,91^{\prime \prime} T\end{array}$ & 1,14 \\
\hline 2 & $\mathrm{~A} 2$ & $\begin{array}{c}4^{0} 55^{\prime} 02,26 " \mathrm{~s} \\
103^{0} 32^{\prime} 01,99^{\prime \prime} \mathrm{T}\end{array}$ & 0,61 \\
\hline 3 & A3 & $\begin{array}{c}4^{0} 55^{\prime} 02,48 " \mathrm{~s} \\
103^{0} 31^{\prime} 58,91^{\prime \prime} \mathrm{T}\end{array}$ & 0,84 \\
\hline
\end{tabular}

Sumber : Data primer, 2014

\section{Material Dasar Perairan}

Material/substrat dasar perairan sangat menentukan kecerahan perairan. Material dasar perairan diukur dengan cara mengamati dasar perairan secara langsung. Dan berdasarkan hasil penelitian bahwa material dasar perairan pantai Laguna adalah adalah karang berpasir.

3. Kecepatan arus

Hasil penelitian kecepatan Arus di Pantai Laguna adalah :

Tabel 9. Kecepatan Arus Pantai Laguna

\begin{tabular}{|c|c|c|c|}
\hline No & Titik Sampling & Titik Koordinat & $\begin{array}{l}\text { Kec. Arus } \\
\text { (m/detik) }\end{array}$ \\
\hline 1 & $\mathrm{~A} 1$ & $\begin{array}{c}4^{0} 55^{\prime} 01,37^{\prime \prime} \mathrm{S} \\
103^{0} 32^{\prime} 04,91^{\prime \prime} T\end{array}$ & 0,053 \\
\hline 2 & $\mathrm{~A} 2$ & $\begin{array}{c}4^{0} 55^{\prime} 02,26 " S \\
103^{0} 32^{\prime} 01,99^{\prime \prime} T\end{array}$ & 0,053 \\
\hline 3 & A3 & $\begin{array}{c}4^{0} 55^{\prime} 02,48^{\prime \prime} \mathrm{S} \\
103^{0} 31^{\prime} 58,91^{\prime \prime} T\end{array}$ & 0,054 \\
\hline & \multicolumn{2}{|c|}{ Kecepatan rata-rata } & 0,053 \\
\hline
\end{tabular}

Sumber : Data primer, 2014 
4. Kecerahan

Hasil penelitian kecerahan perairan di Pantai Laguna adalah .

Tabel 10. Kecerahan Pantai Laguna

\begin{tabular}{|c|c|c|c|}
\hline No & Titik Sampling & Titik Koordinat & $\begin{array}{l}\text { Kecerahan } \\
(\%)\end{array}$ \\
\hline 1 & A1 & $4^{0} 55^{\prime} 01,37^{\prime \prime S} 103^{0} 32^{\prime} 04,91^{\prime \prime} \mathrm{T}$ & 100 \\
\hline 2 & A2 & $4^{0} 55^{\prime} 02,26 " \mathrm{~s} 103^{0} 32^{\prime} 01,99^{\prime \prime T}$ & 100 \\
\hline 3 & A3 & $4^{0} 55^{\prime} 02,48^{\prime \prime S} 103^{0} 31^{\prime} 58,91^{\prime \prime T}$ & 100 \\
\hline
\end{tabular}

Sumber : Data primer, 2014

5. Tipe Pantai

Hasil pengamatan secara visual disepanjang Pantai Laguna merupakan pasir berkarang. Hamparan pasir berkarang tersebut memberikan kesan tersendiri bagi Pantai Laguna untuk kegiatan wisata pantai.

6. Penutupan Lahan Pantai

berdasarkan hasil pengamatan bahwa penutupan lahan pantai Laguna adalah belukar Tinggi.

7. Jarak Ketersediaan Air Tawar

Berdasarkan hasil penelitian bahwa jarak ketersediaan air tawar di Pantai Laguna adalah 60 meter. Menurut Cahyadinata (2009) bahwa ketersediaan air tawar/tanah juga merupakan faktor yang utama dalam kegiatan pariwisata pantai.

Dari hasil pengukuran yang telah diperoleh. Maka peneliti menganalisis kesesuaian berdasarkan aspek penilaian yang disesuaikan dalam tabel parameter kesesuaian wisata pantai untuk memperoleh tingkat kesesuaiannya.

Tabel 11. Hasil analisis kesesuaian wisata pantai

\begin{tabular}{|c|c|c|c|c|c|c|}
\hline Parameter & Bobot & & & & $\begin{array}{l}\mathrm{B} \times \mathrm{S} \\
(\mathrm{Ni})\end{array}$ & $\mathrm{N}$ (maks) \\
\hline Kedalaman(m) & 4 & 0,87 & DP & 4 & 16 & 16 \\
\hline $\begin{array}{l}\text { Material dasar } \\
\text { perairan }\end{array}$ & 4 & $\begin{array}{l}\text { Karang } \\
\text { berpasir }\end{array}$ & DP & 3 & 12 & 16 \\
\hline $\begin{array}{l}\text { Kecepatan } \\
\text { arus (m/det) }\end{array}$ & 4 & 0,053 & DP & 4 & 16 & 16 \\
\hline $\begin{array}{l}\text { Kecerahan } \\
\text { perairan (\%) }\end{array}$ & 4 & 100 & DP & 4 & 16 & 16 \\
\hline Tipe pantai & 7 & $\begin{array}{c}\text { Berpasir, } \\
\text { sedikit karang }\end{array}$ & DP & 3 & 21 & 28 \\
\hline $\begin{array}{l}\text { Penutupan } \\
\text { lahan pantai }\end{array}$ & 3 & Belukar tinggi & DP & 2 & 6 & 12 \\
\hline $\begin{array}{l}\text { Jarak } \\
\text { ketersediaan } \\
\text { air tawar }(\mathrm{km})\end{array}$ & 3 & $0,06 \mathrm{~km}$ & DP & 4 & 12 & 12 \\
\hline \multicolumn{5}{|c|}{ Jumlah } & 99 & 116 \\
\hline
\end{tabular}


Berdasarkan hasil penelitian analisis kesesuaian lokasi wisata di pantai Laguna didapatkan nilai 85,3\%. Ini berarti, Pantai Laguna bagus (sangat sesuai) dikembangkan untuk wisata pantai.

\section{Kawasan Konservasi}

1. Kemiringan.

Berdasarkan hasil penelitian didapatkan kemiringan pantai Laguna dengan kemiringan $13,9^{\circ}$ (landai). Hal ini sesuai dengan pendapat Yulianda (2007) yang menyatakan bahwa. Kemiringan mempengaruhi keamanan seseorang untuk melakukan kegiatan mandi dan renang.

2. Jarak Pantai

Berdasarkan hasil penelitian bahwa jarak pantai pantai Laguna 300 meter dari jalan lintas utama.

3. Jenis Tanah

Berdasarkan hasil penelitian bahwa jenis tanah pantai Laguna Endapan pasir dan lumpur (aluvial pantai).

4. Ketinggian.

Berdasarkan hasil penelitian bahwa ketinggian pantai Laguna 1,05 $\mathrm{m}$ atau $105 \mathrm{~cm}$ dari bibir pantai dan sisi pantai tertinggi

5. Drainase.

Drainase diukur dengan cara mengamati keadaan Draiase yang berada pada pantai tersebut. Berdasarkan hasil penelitian bahwa Draiase pantai Laguna Tidak tergenang

6. Bervegetasi.

Vegetasi pada pantai laguna diukur dengan cara mengamati vegetasi yang hidup pada kawasan pantai Laguna. Berdasarkan hasil penelitian bahwa vegetasi pantai Laguna Non mangrove.

Dari hasil pengukuran yang telah diperoleh. Maka peneliti menganalisis kesesuaian berdasarkan aspek penilaian yang disesuaikan dalam tabel parameter kesesuaian wisata konservasi untuk memperoleh tingkat kesesuaiannya.

Tabel 12. Hasil analisis kesesuaian Kawasan konservasi

\begin{tabular}{lcccccc}
\hline Parameter & Bobot & \multicolumn{2}{c}{ Skor } & & B x S(Ni) & N (Maks) \\
\hline Kemiringan $\left(^{\circ}\right)$ & 0,10 & $13,9^{0}$ & DP & 1 & 0,1 & 0,4 \\
\hline Jarak pantai $(\mathrm{m})$ & 0,30 & 300 & DS & 3 & 0,9 & 1,2 \\
\hline Jenis tanah & 0,15 & Aluvial Pantai & DP & 4 & 0,6 & 0,6 \\
\hline Ketinggian $(\mathrm{cm})$ & 0,10 & $105 \mathrm{~cm}$ & DP & 1 & 0,1 & 0,4 \\
\hline Drainase & 1,15 & Tidak tergenang & DP & 4 & 4,6 & 4,6 \\
\hline Bervegetasi & 0,20 & Non mangrove & DP & 3 & 0,6 & 0,8 \\
\hline & Jumlah & & & 6,9 & 8,0
\end{tabular}

Keterangan : DP (Data Primer), DS (Data Sekunder)

$$
\begin{aligned}
& \mathrm{IKW}=\sum \quad\left[\frac{\mathrm{Ni}}{\mathrm{Nmaks}}\right] \times 100 \% \\
& \mathrm{IKW}=\frac{6,9}{8,0} X 100 \%=86,2 \%
\end{aligned}
$$

Berdasarkan hasil penelitian analisis kesesuaian kawasan konservasi di pantai Laguna didapatkan nilai $86,2 \%$. Ini berarti, Pantai Laguna bagus (sangat sesuai) dikembangkan untuk kawasan konservasi. 


\section{Kesimpulan}

\section{KESIMPULAN DAN SARAN}

Berdasarkan hasil penelitian dapat disimpulkan bahwa Pantai Laguna Desa Merpas dapat dikategorikan sangat sesuai untuk dijadikan sebagai daerah wisata bahari dengan ilai indeks $77 \%$, wisata pantai dengan nilai indeks $85,3 \%$, kawasan Konservasi dengan nilai indeks $86,2 \%$.

Maka disimpulkan Pantai Laguna bisa dikembangkan menjadi tempat pariwisata dan kawasan konservasi. Dikareakan, Suatu kawasan pesisir dapat dikembangkan menjadi daerah pariwisata dan kawasan konservasi secara tersendiri maupun terpadu.

\section{Saran}

Berdasarkan hasil penelitian ini diharapkan kepada semua instansi terkait agar dapat mengembangkan dan memfasilitasi pantai laguna, sehingga dapat dikembangkan dengan lebih baik dan menjadi salah satu sektor unggulan dibidang pariwisata di kabupaten kaur. pantai Laguna Desa Merpas dapat dikembangkan semaksimal mungkin sebagai kawasan konservasi dan sebagai wisata pantai, karena pantai Laguna memiliki potensi yang sangat bagus sebagai kawasan konservasi dan wisata pantai. Oleh karena itu dalam pengembagan pantai laguna sebagai kawasan konservasi dan wisata pantai diharapkan campur tangan pemerintah dan instansi terkait untuk mengelolah pantai laguna sehingga menjadi kawasan konservasi dan wisata pantai yang sesuai dengan potensi yang dimilikinya.

\section{DAFTAR PUSTAKA}

Arifin, T. 2000. Evaluasi Kesesuaian Kawasan Pesisir dan Arahan Pengembangannya bagi Pariwisata bahari di Teluk Palu Propinsi Sulawesi Tengah. Tesis. Program Pascasarjana IPB. Bogor.

Bakosurtanal. 1996. Pengembangan Prototipe Wilayah Pesisir dan Marine Kupang Nusa Tenggara Timur. Pusbina Inderasing Bakosurtanal. Cibinong.

Cahyadinata. 2009. Kesesuaian Pengembangan Kawasan Pesisir Pulau Enggano Untuk Pariwisata Dan Perikanan Tangkap. Bengkulu. Jornal agrisep 24 Desember 2013, 168-182.

Dinas Kelautan dan Perikanan Kabupaten Kaur.2008. Potensi Pantai di Kabupate Kaur. Kaur. Dinas Kelautan Dan Perikanan.

Dinas Kelautan dan Perikanan Kabupaten Kaur. 2009. Profil Wisata Kabupaten Kaur. Kaur. Dinas Kelautan dan Perikanan.

Nurisyah, S. 1998. Rencana Pengembangan Fisik Kawasan Wisata Bahari di Wilayah Pesisir Indonesia. Buletin Taman Dan Lanskap Indonesia. Perencanaan, Perancangan dan Pengelolaan Volume 3, Nomor 2, 1997. Bogor: 133 Studio Arsitektur Pertamanan Fakultas Pertanian Institut Pertanian Bogor 